\title{
Child Participation in Ghana: Responsibilities and Rights
}

\author{
Póra Björnsdóttir and Jónína Einarsdóttir
}

\section{Introduction}

Scholars have long debated the definition of a child and when an individual becomes a youth or an adult. The debate revolves around so-called Western ideas that the life span is divided into clear cut age-based categories such as childhood, adolescence, adulthood and senescent (Eriksen 2001). This life cycle thinking assumes that children, under parental guidance, should enjoy their lives: happy, beloved, well taken care of and protected from hazards (Korbin 2003; Stephens 1995; Such, Walker and Walker 2005). The assumption that childhood is universal and a process every child goes through to prepare for adulthood has been challenged, and scholars argue that it is not a valid claim even in the assumed West (Bucholtz 2002; Liebel 2004). Instead, childhood should be regarded as a social construction or, as James and Prout famously argue, "childhood should be regarded as a part of society and culture rather than a precursor to it; and ... children should be seen as already social actors not beings in the process of becoming such" (James and Prout 2015, xi). Culturally, the boundary between a child, youth and adult can be blurred, which should be taken into account when discussing child-related issues.

The International Year of the Child in 1979 challenged Western ideology of children and childhood. Images of children's harsh living conditions all around the world resulted in increased awareness of child abuse and neglect, and demands for special agreements framing child rights issues (Christiansen and Prout 2005; Korbin 2003). Negotiations resulted in the creation of The United Nations Convention on the Rights of the Child (UNCRC). The UNCRC, which has been adopted by 170 countries, acknowledges children as individuals with their own rights. Some scholars believe the UNCRC has had a great impact on the international agenda and increased awareness of children's rights, their life conditions and future potentials (Doek 2009; Lansdown 2010; UNCRC 1989). Others criticize the UNCRC for universalizing child rights and formulating them in the terms of the minority world while ignoring the conditions, culture 
and customs of children in the majority world (Tisdall and Punch 2012; Korbin 2003; Qvortrup 1994; Stephens 1995; Such, Walker and Walker 2005). Further, there is disagreement on the three key concepts of the UNCRC, that is, protection, provision and participation, and which of these should be given priority (Olesen 2004). Considering that children are still dying from preventable diseases, some scholars argue the focus should be on protection and provision, underlining that children's survival comes first as otherwise they will not live to enjoy any rights (Horton 2004). Meanwhile, others claim more success can be attained if children are aware of their rights and are able to fight for them (Gordon, Nandy, Pantazis, Pemberton and Townsend 2007).

Some scholars, children's advocates and aid workers believe that with the increased participation of the intended beneficiaries, the implementation of projects, legislations and agreements will be more successful (Mikkelsen 2005; UNHCHR 2006). The participation concept has, however, created political tension within the development aid discourse; some claim participation to be critical for successful implementation while others are concerned with what they call the 'tyranny' of participation (Baaz 2005; Brown 2004; Cooke and Kothari 2002). Despite critique of the UNCRC and the concept of participation, in the wake of the UNCRC children are reported to have become more aware of their rights and are increasingly fighting for them (Doek 2009; Coly and Torenzio 2007; Ehlers and Frank 2008; Honwana 2013). Likewise, participation has increasingly become popular among international and local development agencies and non-governmental organizations (NGOS) (Hart 2013; Lansdown 2010).

This chapter examines the participation of children and youth in Ghana in projects executed around the country, mostly by local authorities, NGOs and governmental organizations. Since independence in 1957, Ghana has been considered a forerunner among African states in good governance and democracy. In past years, the government has focused on human and child rights and declared its intention to improve future potentials of young people in the country. Many agreements that, to some extent, cover child and youth participation and acknowledge children as individuals with agency and the capacity to express their views have been ratified and legislated. Participatory projects can be found all around in the country and most of these are sponsored or have been established by government institutions, international and local development agencies and NGOs (Björnsdóttir 2011).

The chapter rests on fieldwork in Ghana carried out from September to December 2010 (Björnsdóttir 2011). Data collection was based on qualitative methodologies, including participant observation, focus group discussions, visual methods and interviews. The participants in the study were girls and boys aged 6-18 years from urban and rural areas and youth aged 19-28 who 
were and had been involved in participatory projects since an early age. Young people aged 13-19 comprised the majority of the participants in the research. Additional participants were adults working within governmental institutions, organizations and NGOs who aimed to enhance children's right to participate in Ghana. The research focuses mainly on three types of participatory projects where children and youth are given the opportunity to learn about their rights and share their knowledge with other members of society. The first are the child rights clubs that can be found in most schools in the country. The second type is represented by the radio program Curious Minds that is hosted by children and youth. The third type includes three bigger events: The Constitutional Review Commission, Global Handwashing Day and Ghana Water Forum, all of which aim to create platforms for children and young people to express themselves at the national level.

This chapter intentionally blurs the boundary between a child and a youth, as we wish to explore how young people perceive and utilize the idea of child participation. We begin with a presentation of the benefits of participation and thereafter treat the barriers to its realization. Then we outline an approach that aims to overcome the barriers for the benefit of all parties. Finally, we focus on adult involvement in participatory projects and its implications.

\section{Benefits of Participation}

According to scholars, participation can benefit both children and the society in various ways. Participation is believed to increase democratic understanding and rights among young people and support their future potential (Ansell 2005; Ehlers and Frank 2008). Furthermore, research indicates that participation gives children and youth an increased sense of competence and confidence, and adults gain an understanding of children's lives and become more sensitive and positive towards their opinions (Ansell 2005; O'Kane 2003). The participants in our study agreed with these advantages of participation, further arguing that it was beneficial for children themselves as well as their society. Most claimed to enjoy participation and said that they were engaged in such projects mostly for own pleasure. Children and youth in the child rights clubs and Curious Minds agreed that by being involved they had made new friends and been able to socialize with others, which brought happiness into their lives. They were also able to discuss and share their problems with others without being criticized. Those who participated in the bigger events were happy with meeting new people but they also enjoyed the experience of travelling and being allowed to be part of an event on a national level. Furthermore, 
they also argued that their involvement in participatory projects benefited themselves and other members of the society both from a short and long term perspective.

Many children and youth, in all programs, believed participation could increase their future opportunities. By being involved in participatory programs, as explained by a fifteen year old girl in a children's rights club, she would get more confidence and learn to speak in front of many people, both young and old. Furthermore, worrying about how others would react to her opinions would no longer prevent her sharing them. According to a sixteen-year-old girl, increased confidence would not only help in improving a child's current life but also contribute to better opportunities in the future, for example in getting a good job. Other children, and indeed adults as well, agreed that participation enhanced children's future opportunities. Furthermore, as mentioned by a thirteen-year-old boy, participation could help others. A child who was confident would be more likely to share his or her knowledge by educating others about child rights and raising awareness about child-related issues. Accordingly, he argued, other children would become more aware of their rights as, most likely, would other community members as well.

Both girls and boys agreed that they would learn critical thinking through participation and therefore their views would sound more sensible to adults, making it easier for adults to understand and approve their opinions. Because of the skills they had developed through participatory projects, the children also felt more accepted and acknowledged, further increasing their chances of being involved in decision-making, sharing their opinions and having a voice in society. One fourteen-year-old girl argued that children were clever and fully capable of discussing their own rights and views, and most often they did so better than adults. Therefore, by making all members of society aware of the importance of children's participatory rights, their future opportunities would not only increase but they would also develop important skills and abilities which would benefit them and their society as whole. The children themselves could educate and inform other members of society about their rights, thereby affecting future generations and making the community better prepared and educated to deal with child-related issues in a relevant way.

Many of the children who were involved in participatory projects also spent time volunteering and educating other children about their rights. They argued that through involvement in the projects they were more likely to understand and listen to each other. Further, as the number of children aware of child rights increased, the risk of someone depriving children of their rights would lessen. One girl who was active in an urban rights club believed that by being involved children could become 'voices for the voiceless' and consequently help those 
unaware or deprived of their rights. Another aspect that could benefit the society was children's integrity. Both adults and children considered children to be honest, sincere, truthful and not easily corrupted by other members of society. This meant that children would bring new or different aspects into discussion, which would probably be missed out without their participation.

\section{Barriers to Child and Youth Participation}

The positive aspects of child participation identified by the children mostly coincide with the scholarly literature (Ansell 2005; Lansdown 2010; O'Kane 2003). However, the children identified three main barriers to their becoming true participants in their society. Firstly, they blamed the Ghanaian culture, more specifically its emphasis on age hierarchy and traditions of punishing children. Secondly, adults were regarded as being uneducated and in need of better knowledge of the positive aspects of child participation. Finally, the authorities were criticized for neglecting implementation and follow-up of adopted legislation, an issue also treated by scholars (Lansdown 2010; Malone and Hartung 2010). These barriers, identified by both children and adults, were assumed to impede child participation in Ghana, and prevent NGOs and governmental institutions from promoting truly child-friendly participation.

Cultural norms were believed to be a barrier to the participation of children in the country's organization, though none of the participants argued they should get rid of their culture. The barriers identified by the children and youth were related to adults' ideas and interventions. Respectful behaviour towards elders is a cultural tradition that should not be sabotaged, adults and children argued. Some of the children claimed that adults believed if children were given too much space in society, their own voices would be less valued and respected. Both girls and boys argued that adults disliked child rights in general and they had no intention or desire to accept child participation. Most of the children were confident that adults who feared or spoke out against child rights and participation did so because they were uninformed on the content of child participation. Adults did not understand the meaning or purpose of such participation for children and society. A young girl aged seventeen living in an urban area said, for instance, that her parents were not happy when she became active in participatory projects, thinking that she would become arrogant, stubborn and disrespectful towards elderly people. However, when they realized that her involvement did not change her for the worse, they began to approve of participation and admire her ability and finally they appreciated her engagement with participatory activities. 
Both children and youth agreed that a hierarchy based on age was prevalent at all levels, including within local communities, the government and the school system. In some cases, children might be prevented from speaking, making decisions or even having their own opinions about certain issues. Children were categorized as ranking below other members in society, they said. They were afraid of speaking out and instead tended to hold back their views so they would not be punished for having expressed the wrong opinion. A fourteen-year-old boy from a rural area pointed out that young people tended to restrain their feelings and opinions to avoid corporal punishment. Children were afraid of sharing views with others, especially adults, because there was a chance of being beaten for having different ideas than those held by adults. Indeed, he believed caning had forced some children to quit school because of the fear they had for the teacher or other adult workers at the school.

Lastly, children and youth, along with adults supporting child rights, mentioned that the authorities had failed to implement some agreements and laws. Although the parliament had put considerable efforts into creating a platform from which children could speak out, and ratifying and forcing agreements into law, less focus had been directed towards following up the legislation. A young girl said governmental institutions in Ghana were successful in ratifying laws and agreements but following up on the implementation was not performed as needed. Further progress of children's participation in Ghana is therefore dependent on the authorities. Political changes at the national level are needed as well as the will to improve the participation of children and accept their involvement, views and opinions.

The Ghanaian children criticized the authorities for being ambiguous towards child rights and children's increased participation in their society. The authorities were seen as more interested in enhancing their own power and creating a positive image for outsiders than promoting child rights. Similarly, Ako, Ayidoho and Crafword (2014) found that the rights-based approach as a strategy to enhance the rights of economically disadvantaged people in Ghana was challenged by the national structure and traditional authorities. They suggest that sharing of power and cooperation between relevant partners could be a solution. The participants in our research also identified cooperation between adults and children as a way forward. In addition, they suggested ways of dealing with the cultural values that were identified as barriers to child participation.

\section{Rights Come with Responsibilities}

Lansdown (2010) argues that one of the main problems in implementing the participation of children in projects is the lack of an explicit definition of the 
concept; scholars have mostly just described participation as 'involvement in daily activities' (see Alderson 2008). In order to narrow the definition of child participation a number of elements of what this means should be stressed: children must have a voice, take part in decision-making and be recognized as individuals (Hart 1992; Lansdown 2010, 1997; Treseder 1997), and not least, children and youth should be treated as "engaged actors rather than passive beneficiaries" (Ehlers and Frank 2008, 38). Thus, in participatory projects, the focus is partly on children's agency and initiatives, and partly on the training and skills of the child rights proponents. However, what constitutes an adequate role for adults in participatory projects for children, and to what extend children should be allowed to participate remains unclear.

Some scholars believe cooperation between adults and children to be crucial for implementation of participatory projects (Blanchet-Cohen and Bedeaux 2014; Ehlers and Frank 2008). Wyness $(2013,12)$ maintains that participatory projects are "about how children's voices can be heard and acknowledged through more interconnected relations between children and adults". One of the vital aspects of successful cooperation in participatory projects is that children are allowed to influence decision-making processes and that adults accept them as full members (O'Kane 2003). Likewise, Alderson $(2008,87)$ underlines that there must be appropriate balance and guidance "between protection and respect for the child autonomy; providing too little or too much adult support; helping children towards independence too early or too slowly; the child's and the parents and other people's rights, interests and welfare". In Ghana, cooperation between children and adults in participatory projects has been advocated and attempts made to implement such projects. For that purpose, the child right advocates launched the approach 'rights come with responsibilities'. The aim is to have the general public accept child participation and to counteract the identified barriers. The approach underlines that while having rights, children also have to understand their duties towards the family and the society. Thus, increased rights do not give children and youth permission to be disrespectful towards adults or any other community member. Accordingly, children are to be taught about their responsibilities and how these differ from rights. For example, children have the right to go to school but they also have the responsibility to attend school and to do their homework.

The children and youth who participated in the study usually accepted that rights come with responsibilities. However, some of them, especially the younger children living in rural areas, had difficulties in distinguishing between these terms. The adults, on the other hand, had no problem in recognizing the difference between rights and responsibilities and used the approach as a way to control child participation and the discourse of child rights in the country. As mentioned by an NGO male adult, although children had the right 
to participate, the concept of child rights should not be separated from their responsibilities. Their participation also had to be controlled. Otherwise there was a risk of children getting 'spoiled' and without control adults would neither understand nor accept child engagement.

Child rights advocates, both the young and adults, agreed that education of the general public was needed to advance children's rights and increase their participation. At the same time the main pillars of Ghanaian society should be kept intact. Here, the hierarchy of age was seen as the trickiest issue. The argument was that children's participation need not interfere with the cultural values of Ghana; rather, participation would help both children and other community members to become aware of child rights and fight for them. Through cooperation both adults and children would gain what they aimed for, though the question arises as to how such cooperation affects the balance of power between children and adults negatively for the children. Furthermore, the approach 'rights with responsibilities' is likely to enhance adult involvement.

\section{Adult Involvement}

Adult intervention has been documented as a challenge to children's true participation due to the tendency of adults to underestimate children's capacity and agency (Lansdown 2010; Malone and Hartung 2010). Some adults assume that children are immature, irrational, irresponsible or incapable of making decisions concerning their own lives (Alderson 2008; Lansdown 2010; Driskell 2002; Malone and Hartung 2010; Treseder 1997) and consequently feel obligated to guide them in the 'right' direction. As a result of adults demanding certain behaviour, participation tends to become adult-centred instead of child-focused (Bordonaro and Payne 2012, 368). In addition, Treseder (1997) argues that people seem to like the idea of child participation as such, but not in practice. Adult's fear of children becoming too active, independent and confident has been identified as one of the main obstacles to child participation. The adults included in the study were either state employees or NGO representatives, and they all regarded themselves as genuine advocates of child rights. Nevertheless, some of them agreed with the above but also mentioned that children are unable to make decisions and share their views because of their immaturity, which consequently instilled a greater need to intervene.

Adult interference in the three projects under analysis depended greatly on the nature of the project, and the events in which the children participated. The bigger events, like the Constitutional Review Commission, tended to be formal and more controlled by adults than the other projects. The children 
and youth who participated in these events were expected to behave in a decent and respectful way. The participants in such events were aged 6-18 and originated from both rural and urban areas of Ghana and were most often chosen to participate by a teacher or other adults in the community according to guidelines supplied by the relevant organization. A statement was sent out by the organizations to community schools listing the number of children needed, broken down according to gender, rural, urban and disabled, in order to have as diverse a group as possible, though this depended on the level of the event. For example, older and more educated children were chosen for The Constitutional Review Commission than for the other events. When it came to a school's decision of which child should participate, the child's school enrolment and grades counted heavily. For children living in rural areas, the bigger events required travel to cities and participation might take up to two or three days, during which time they were out of school. This meant that a child who was not considered clever or confident by teachers was normally not allowed to participate on the basis that such children should be protected from accruing even greater difficulties in school. Instead teachers chose children who they believe would be able to contribute to the debate and consequently to the good reputation of their school and hometown.

Adult selection of children, such as described here, applied only to child participation in the bigger events. All children interested in child rights issues were allowed and encouraged to join and participate in the child rights clubs in their school from primary to senior educational levels. However, some children complained that their families, especially parents, were not thrilled about their participatory involvement from the start, claiming they would get spoiled or stubborn. The child rights clubs were less formal than the bigger events and the children had more liberty to behave freely and to speak out about their personal opinions. However, the clubs were managed by adult teachers or 'patrons' and the degree to which they allowed children to express themselves and how much the conversations were controlled and the children's opinions were 'corrected' varied greatly between places. The differences relied mostly on the views, focus and interest in the topic of the respective adults rather than the children's social and cultural status or their views and opinions.

In contrast to the child rights clubs, the Curious Minds radio program was almost without adult control and interference. From the beginning the children and youth who participated in Curious Minds were aged 8-18, although at the time of the research the majority were young people aged 14-25. Most of the participants were born and raised in Accra. The youth chose the topic they believed was important to discuss and organized a meeting, which was then aired. They discussed the topic on radio without any adult interference. 
The group was, however, under the guidance of one adult whose only duty was to make sure everything was fine and the broadcasting went smoothly.

In the above-mentioned projects, especially the bigger events, adults tended to underestimate children's agency and capacity. Many of the adults were surprised to see and hear the extent to which the children and young people had contributed and admitted that the participation of the latter had increased their respect for children's opinions and capacity. A middle-aged male governmental participant claimed that it would not be possible to ignore children's voices after listening to how smart and sensible they were. A female governmental worker maintained that the organizers of child participation should make sure that the children were not 'brainwashed' by adults before they participated in bigger events; most important was that their voices were definitely heard. Ultimately, all adults participating in the study agreed on the importance of the right of children to participate. They argued that, as human beings, children should be respected as individuals and citizens and be allowed to become involved in society like everyone else. As one female organization worker said:

They have to talk and discuss what the national development issues are ... They are human beings themselves and should participate in these discussions ... We are getting to the level that we are respecting the voice of children ... It is not seen as an obligation but it is respected and listened to as well.

Children were referred to as 'the future' and as those who would hold power over the next generations. In one child rights club the children were taught a song with the slogan, "We are the future leaders, we are the union of the country". Therefore, according to adult interviewees in the study, it was extremely important to give children a platform from which to speak out, and share their feelings and opinions on matters affecting them. The adults argued that participation could broaden children's minds and allow them to gain understanding of national issues, shaping who they were and who they would become in the future.

Child rights advocates agreed that child rights were increasingly being accepted in Ghana and children were becoming less afraid of being involved. Overall, the adult child advocates believed that young people should be involved in the whole process from preparation to monitoring, analysing and finally decision-making and implementing projects dealing with child-related issues, although there was some lack of congruence concerning who was honestly interested in child rights and participation. The NGO workers pointed 
out that the importance attributed to children's views and opinions did not necessarily mean that children's voices would always be taken into account. They argued that, frequently, the higher levels of state authorities ignored children's voices, and were generally uninterested in taking children seriously except when using their ideas in some 'final product' such as project proposals and plans, laws and child-rights covenants. Hence, mainly to look good on the surface, the authorities would argue that involving children was important. The child rights proponents used the phrase 'children should be seen but not heard' to express the authorities' real ideas and intentions when it came to child participation. Children were expected to be visible and share brief views on certain topics to thereby enhance the positive image of the stakeholders. However, in the end, adults should make the decisions while children's role was to sit, listen and learn.

While criticizing the state authorities for paying lip service to children's participation, the child rights advocates acknowledged that children's full participation could be complicated in practice, even when there was a genuine will for its implementation on everyone's part. The full participation of children was costly and time consuming to implement. It was also difficult to ensure that all children could be equally enabled to participate, for instance in urban and rural areas, among boys and girls, young and older alike, and so on. When only urban children were involved, NGOs were accused of discriminating against those living in rural areas.

O'Kane (2003) has pointed out that a lack of common definition and the complexity of the concept of participation has made it difficult for child rights proponents to implement such projects. Furthermore, in line with worries expressed by Landsdown (2010), Malone and Hartung (2010) and Bordonaro and Payne (2012), in practice child participation observed in Ghana was partly dictated by adult involvement. The UNCRC states that all children should be allowed to take part in line with their age and capacity, but how do we know when a child is old enough or capable? The decision as to which child should have the opportunity to participate lies mostly in the hands of adults who make a choice based on their evaluation of the children's individual capacity: that is, proper behaviour, intelligence or performance at school.

\section{Conclusion}

The aim of this chapter is to shed light on the participation of children and young people in Ghana from the viewpoint of adult child rights advocates and young participants. Many platforms have been created in the country from 
which children and youth may share opinions on matters concerning them. The study results show that both adults and young people believed these platforms to be a positive improvement for child rights since participation can be beneficial both in present time and in the future. However, cultural traditions, including the age-based hierarchy, were considered a barrier to children's participation. To be able to implement young people's participation without sabotaging the cultural traditions, child rights proponents have emphasized that with rights come responsibilities, an approach also designed to gain approval among the general public. At the same time, it is likely to strengthen adult involvement, although this varies according to the age of participants and the kind of participatory project.

Although some child rights advocates and scholars believe in child participation, others argue that true participation of children is difficult to attain (Baaz 2005; Brown 2004; Cooke and Kothari 2002; Mikkelsen 2005). While our study shows some success in implementing participatory projects for children and youth, there are still hindrances to overcome. Furthermore, the adult child advocates in the study pointed out that child participation is not only complicated but also expensive to implement. Sill, Hart $(2008,418)$ blames donors and NGOS when he points out that participatory projects tend to fail. He argues that the involved organizations aim "to manage the effects of underdevelopment rather than to achieve meaningful transformation of political and economic realities" (Hart 2008, 416). In a similar vein, Rahman (2010) observes that, indeed, adult involvement in participatory projects is ambiguous and wonders if the training provided by adults is helpful considering that adult absence might be more effective. While blaming the higher authorities for paying lip service to child participation, the adult child rights advocates seem to be unaware of their own manipulation of child participation. This applies in particular to the younger age group, which tended to be more led and controlled by adults while the youth participated more freely.

Further research on child participation is needed, including exploration of its forms, extent, benefits and barriers. While the adult child rights advocates, youth and children in the current study agreed about the benefits of child participation, children's life conditions, educational achievements and age influenced their participation. Is child participation, as it is currently organized by governmental institutions and NGOS, there for everyone? Hart (2008) is concerned with realization of political changes that require political will, renewed alliances and children's participation on their own terms. According to Hart, children must become recognized as political actors, which begs the question: Is real participation of children and young people possible without major societal changes? 


\section{References}

Ako, Matilda A., Nana A. Anyidoho, and Gordon Crafword. 2014. "NGOs, Rights-Based Approaches and the Potential for Progressive Development in Local Contexts: Constrains and Challenges in Northern Ghana." Journal of Human Rights Practice 5 (1): 46-74.

Alderson, Priscilla. 2008. Young Children's Rights: Exploring Beliefs, Principles and Practice. London and Philadelphia: Jessica Kingsley Publishers.

Ansell, Nicola. 2005. Children, Youth and Development. Abingdon: Routledge.

Baaz, Maria E. 2005. The Paternalism of Partnership: A Postcolonial Reading of Identity in Development Aid. London and New York: Zed Books.

Björnsdóttir, Póra. 2011. "Children are agents of change: Participation of children in Ghana." Masters' thesis, University of Iceland, Reykjavik.

Blanchet-Cohen, Natasha, and Christophe Bedeaux. 2014. "Towards a Rights-Based Approach to Youth Programs: Duty-Bearers Perspectives." Children and Youth Services Review.

Bordonaro, Lorenzo I., and Ruth Payne. 2012. "Ambiguous Agency: Critical Perspectives on Social Interventions with Children and Youth in Africa." Children's Geographies $10(4): 365-372$.

Brown, David. 2004. "Participation in Poverty Reduction Strategies: Democracy Strengthened or Democracy Undermined?" In Participation from Tyranny to Transformation?: Exploring New Approaches to Participation in Development, edited by Samuel Hickey and Giles Mohan, 237-251. New York: Zed Books.

Bucholtz, M. 2002. Youth and Cultural Practice. Annual Review of Anthropology 31: $525-55^{2}$.

Christiansen, Pia, and Prout, Alan. 2005. "Anthropological and Sociological Perspectives on the Study of Children." In Reaching Children's Experience: Approaches and Methods, edited by Sheila Greene and Diane Hogan, 42-61. London: Sage Publications Ltd.

Coly, Hamidou, and Fabrizio Terenzio. 2007. "The Stakes of Children's Participation in Africa: The African Movement of Working Children and Youth." In Working to Be Someone: Child Focused Research and Practice with Working Children, edited by Beatrice Hungerland, Manfred Liebel, Brian Milne and Anne Wihstutz, 179-186. London and Philadelphia: Jessica Kingsley Publishers.

Cooke, Bill, and Uma Kothari. 2002. Participation: The New Tyranny? London:Zed Books. Doek, Jaap E. 2009. "The CRC 20 years: An Overview of Some of the Major Achievements and Remaining Challenges." Child Abuse \& Neglect 33: 771-782.

Driskell, David. 2002. Creating Better Cities with Children and Youth: A Manual for Participation. London: United Nations Educational, Scientific and Cultural Organization and Earthscan Publications Ltd. 
Ehlers, Louise, and Cheryl Frank. 2008. "Child participation in Africa." In Children's Rights in Africa: A legal Perspective, edited by Julia Sloth-Nielsen, 111-128. Hampshire: Ashgate Publishing Limited.

Eriksen, T.H. 2001. Small Places, Large Issues: An Introduction to Social and Cultural Anthropology. London: Pluto Press.

Gordon, David, Shailen Nandy, Christina Pantazis, Simon Pemberton, and Peter Townsend. 2007. "Child Rights and Child Poverty: Can the International Framework of children's Rights Be Used to Improve Child Survival Rates?” PLoS Medicine 4 (10): 1567-1570.

Hart, Roger A. 2013. Children's Participation: The Theory and Practice of Involving Young Citizens in Community Development and Environmental Care. New York: Taylor \& Francis.

Hart, Jason. 2008. "Children's Participation and International Development: Attending to the Political." The International Journal of Children's Rights 16 (3): 407-418.

Hart, Roger A. 1992. "Children's Participation: From Tokenism to Citizenship." Innocenti essays, No. 4. Florence: UNICEF.

Honwana, Alcinda. 2013. "Youth, Waithood, and Protest Movements in Africa." Paper presented at the Fifth European Conference on African Studies, Lisbon, Portugal, June 28.

Horton, Richard. 2004. "UNICEF Leadership 2005-2015: A Call for Strategic Change". The Lancet 364, no. 9451: 2071-2074.

James, A., and Prout, A. 2015. Constructing and Reconstructing Childhood: Contemporary Issues in the Sociological Study of Childhood. Abingdon and New York: Routledge.

Korbin, Jill E. 2003. "Children, Childhoods, and Violence." Annual Review of Anthropology 32: 431-447.

Lansdown, Gerison. 2010. “The Realisation of Children's Participation Rights." In $A$ Handbook of Children and Young People's Participation, Perspectives from Theory and Practice, edited by Barry Percy-Smith and Nigel Thomas, 11-23. New York: Routledge.

Lansdown, Gerison. 1997. "Children's Rights to Participation: A Critique." In Participation and Empowerment in Child Protection, edited by Christopher Cloke and Murray Davies, 19-38. Sussex: John Wiley \& Sons.

Liebel, M. 2004. A Will of Their Own: Cross-Cultural Perspectives on Working Children. London and New York: Zed books.

Malone, Karen, and Catherine Hartung. 2010. "Challenges of Participatory Practice with Children." In A Handbook of Children and Young People's Participation: Perspectives from Theory and Practice, edited by Barry Percy-Smith and Nigel Thomas, 23-38. New York: Routledge.

Mikkelsen, Birtha. 2005. Methods for Development Work and Reasearch: A New Guide for Practitioners. New Delhi: Sage Publications.

O'Kane, Claire. 2003. "Street and Working Children's Participation in Programming for their Rights." Children, Youth and environments 13 (1): 2-17. 
Olesen, Jesper. 2004. "Budget Management of Childhood." In Beyond the Competent Child: Exploring Contemporary Childhoods in the Nordic Welfare Societies, edited by Helene Brembeck, 275-292. Roskilde: Roskilde University Press.

Qvortrup, Jens. 1994. “Childhood Matters: An introduction." In Childhood Matters: Social Theory, Practice and Politics, edited by Jens Qvortrup and Marjatta Bardy, 1-24. Aldershot: Avebury.

Rahman, Khandaker F. 2010. "Linkage between Right to Development and Rightsbased Approach: An Overview." The Northern University Journal of Law, 1: 96-111.

Stephens, Sharon. 1995. "Introduction: Children and the Politics of Culture in 'Late Capitalism." In Children and the Politics of Culture, 3-48. Princeton: Princeton University Press.

Such, Elizabeth, Oliver Walker, and Robert Walker. 2005. "Anti-War Children." Childhood $12(3): 301-326$.

Tisdall, E. Kay M, and Samantha Punch. 2012. "Not so 'new'? Looking Critically at Childhood Studies." Children's Geographies 10 (3): 249-264.

Treseder, Phil. 1997. "Involving and Empowering Children and Young People: Overcoming the Barriers." In Participation and Empowerment in Child Protection, edited by Christopher Cloke and Murray Davies, 207-231. Sussex: John Wiley \& Sons.

UNHCHR. 2006. "Frequently Asked Questions on a Rights-Based Approach to Development Cooperation." New York and Geneva: The United Nations.

United Nations. 1989. "The United Nations Convention on the Right of the Child (UNCRC)."

Wyness, Michael. 2013. "Children's Participation and Intergenerational Dialogue: Bringing Adults Back into the Analysis." Childhood 20 (4): 429-442. 